Gut, 1987, 28, 26-32

\title{
Evaluation of gastric carcinoembryonic antigen analysis as an aid during screening for gastric neoplasia in atrophic gastritis
}

\author{
K BORCH, H RENVALL, CHRISTINA LUNDIN, AND B WAHREN \\ From the Departments of Surgery and Pathology, Central Hospital of Eskilstuna, and the Department of \\ Virology, National Bacteriological Laboratory, Stockholm, Sweden.
}

SUMmARY The value of gastric juice and tissue carcinoembryonic antigen (CEA) analysis as an adjunct to endoscopic screening for gastric neoplasia was investigated in 61 patients with atrophic gastritis of whom 41 had other (superimposed) gastric lesions: six adenocarcinoma, four carcinoid, 23 regenerative polyps with or without dysplasia and eight fundic, or antral mucosal dysplasia. The gastric concentration of CEA did not differ between patient groups with different superimposed lesions. In these patients the gastric juice CEA concentrations were significantly increased in comparison with those in patients without superimposed lesions $(p=0 \cdot 002)$. Gastric juice CEA concentrations above the upper range $(+2 \mathrm{SD})$ of those observed in normal controls were found in $40(98 \%)$ of 41 patients with superimposed lesions and in $13(65 \%)$ of 20 patients without such lesions $(\mathrm{p}=0.001)$. At re-examination of 26 patients without neoplasia initially, after a mean interval of 32 months two (without polyps initially), had developed regenerative polyps, one an adenoma, and one an adenocarcinoma. These four had raised gastric juice CEA concentrations at the initial examination.

Since the detection of carcinoembryonic antigen (CEA) in cancer of entodermal origin by Gold and Freedman in $1965,{ }^{12}$ it has become evident that, although being of value in screening for regression or progression of known CEA producing malignant disease ${ }^{3}$ analysis of circulating CEA is of limited value in screening for cancer. Increased circulating concentrations of CEA may occur in benign or premalignant digestive disease, in benign and malignant disease of non-entodermally derived organs, in pregnancy, and in smokers. ${ }^{4-6}$ Determination of CEA at a local level seems to provide more relevant information than analysis in blood. ${ }^{7-12}$

As concluded in the literature ${ }^{7}$ and in the Consensus Development Conference Statement at the US National Institutes of Health in 1980, 'the use of CEA to assist with surveillance of socalled high-risk groups, in whom CEA producing tumours may develop, remains to be established'. ${ }^{3}$ According to several authors, increased production of CEA

Address for correspondence: Kurt Borch, MD, Department of Surgery, University Hospital, S-58185 Linköping, Sweden.

Received for publication 2 May 1986 occurs in most gastric adenocarcinomas, and in atrophic gastritis. ${ }^{13-23}$ Patients with atrophic gastritis run an increased risk of developing gastric adenocarcinoma, as well as gastric carcinoid tumours and, accordingly, constitute a high risk group. ${ }^{2-31}$ The value of CEA analysis during surveillance of these patients has not been fully investigated.

In the present series of patients with atrophic gastritis, the use of gastric CEA analysis as an aid to the identification of individuals with - or at special risk of developing - premalignant or malignant gastric lesions, was evaluated.

\section{Methods}

PAT I E N T S

During initial gastroscopic screening of patients with atrophic gastritis as previously described, ${ }^{24} 61$ patients (mean age 68.5 years, range $41-80$ years, male to female ratio 0.7 ) were investigated for gastric CEA. No extra-gastric disease, known to be associated with increased production of CEA had been diagnosed. Of these patients, 41 had pernicious anaemia, verified according to previously 
described criteria, ${ }^{32} 12$ achlorhydric fundic atrophic gastritis without pernicious anaemia, and eight hypochlorhydric fundic atrophic gastritis (BAO:0-1.0 mmol/h, PAO:0.7-6.1 $\mathrm{mmol} / \mathrm{h}$, according to pentagastrin test). Of all 61 patients with atrophic gastritis, six had gastric adenocarcinoma, four carcinoid tumours, 23 one or several regenerative (non-neoplastic) polyps with or without dysplasia, eight fundic or antral mucosal dysplasia, and 20 had no such lesions. Six patients with benign gastric ulcer and slight or no mucosal atrophy (age 41-80 years) and eight normal control subjects (age 23-79 years) (normal results of pentagastrin test and histologically normal gastric mucosa) were also investigated after informed consent.

Of a larger group of endoscopically re-examined patients with atrophic gastritis, all without neoplasia at the initial examination, ${ }^{25} 26$ had previously been examined for gastric CEA.

\section{GASTROSCOPY, BIOPSY, AND HISTOLOGICAL EXAMINATION}

Gastroscopy, collection of multiple standardised biopsy specimens and blood samples were carried out, as previously described. ${ }^{24}$ Gastric juice was collected in the fundus (patient in left side position) with a catheter introduced through the gastroscope. Gastric juice was immediately frozen at $-70^{\circ} \mathrm{C}$, as were multiple fresh fundic and antral mucosal biopsy specimens, and multiple biopsies from neoplasias, polyps, and the margin of benign ulcers. Several of these lesions were endoscopically or surgically removed. The mean wet weight of tissue samples from each area or local lesion was $7.0 \mathrm{mg}$ (range 2.1-74.6 mg).

Biopsy specimens taken close to the spots biopsied for quantitative analysis were fixed in Lillie's fixative $^{33}$ for immunohistochemical examination and staining with haematoxylin-eosin and Alcian blue $(\mathrm{pH} \mathrm{2 \cdot 5).} \mathrm{Gastric} \mathrm{mucosal} \mathrm{atrophy,} \mathrm{intestinal} \mathrm{meta-}$ plasia, inflammatory infiltrate, and epithelial dysplasia were classified as slight, moderate, or severe. ${ }^{34-36}$

Of the six gastric adenocarcinomas, one was of the diffuse type and the remaining of the intestinal type. ${ }^{37}$ Four intestinal type carcinomas were early lesions. ${ }^{38}$ The endoscopic, histologic, and ultrastructural features of the gastric carcinoids, all of which were argyrophil, non-argentaffin tumours have previously been reported. ${ }^{24}$

\section{RADIOIMMUNOASSAY AND}

IMMUNOHISTOCHEMICAL ANALYSIS

Rabbit anti-CEA (non-reactive with normal crossreactive antigen NCA 1 and bile glycoprotein BGP I) absorbed with human $\mathrm{AB}+$ erythrocytes, was used. ${ }^{39} \mathrm{~A}$ double antibody solid phase radioimmunoassay (RIA) was used for quantification. ${ }^{40}$ The tissue samples were weighed, mixed with $160 \mu \mathrm{l}$ distilled water, homogenised for five minutes with a Dounce ${ }^{\circledR}$ homogeniser, and $40 \mu \mathrm{l} 4.5 \% \mathrm{NaCl}$ was added. This suspension was analysed in the RIA in dilutions of phosphate-buffered saline (PBS) with $1 \%$ bovine serum albumin. Gastric juice was analysed in the same diluent. Serum was assayed without perchloric acid extraction. Normal values for healthy subjects $(n=100)$ with this RIA and non-PCA extracted samples are $<25 \mathrm{ng} / \mathrm{ml}$.

Immunohistochemical staining for CEA was carried out according to the peroxidase-antiperoxidase technique ${ }^{41}$ using the same antibody as in the RIA. Endogenous peroxidase activity was blocked with $30 \% \mathrm{H}_{2} \mathrm{O}_{2}$ in methanol. To minimise background staining, the sections were incubated for 20 minutes with normal swine serum diluted 1:4 in PBS. The antibody incubation procedure was done with rabbit anti-CEA serum diluted 1:100 in PBS (30 min), swine antirabbit serum diluted 1:100 in PBS (30 $\mathrm{min}$ ), and rabbit peroxidase-antiperoxidase diluted 1:200 in PBS (30 min). Staining was developed in a PBS solution of diaminobenzidine and $\mathrm{H}_{2} \mathrm{O}_{2}$ (7 min). Parallel sections treated with normal rabbit serum instead of rabbit anti-CEA served as controls. Thorough washing in PBS was carried out between the steps. Sections were counterstained with haematoxylin.

\section{STATISTICAL ANALYSIS}

The Mann-Whitney test was used for comparison between groups. Analysis for correlation was carried out by simple linear regression analysis and Spearman rank correlation analysis, and $r$ or $r_{s}$ was tested in the $t$ distribution. Differences in proportions between groups were analysed with the $\chi^{2}$ test corrected for continuity. All given values of $p$ are based on two-tailed tests and $\mathrm{p}>0.05$ is considered not significant (NS). Mean values are given with \pm standard error of the mean (SEM).

\section{Results}

\section{IMMUNOHISTOCHEMICAL ANALYSIS}

No CEA staining was observed in the fundic or antral mucosa in normal controls. In moderate or severe atrophy, the general picture was that of a linear CEA staining in the glycocalyx and, to a varying extent and intensity, in the cytoplasm of the columnar cells in the surface and foveolar epithelium (Fig. 1). In the fundic mucosa of approximately half of the cases with atrophic gastritis, a granular cytoplasmic CEA staining was seen in single or groups of cells in a varying number of glands with or 

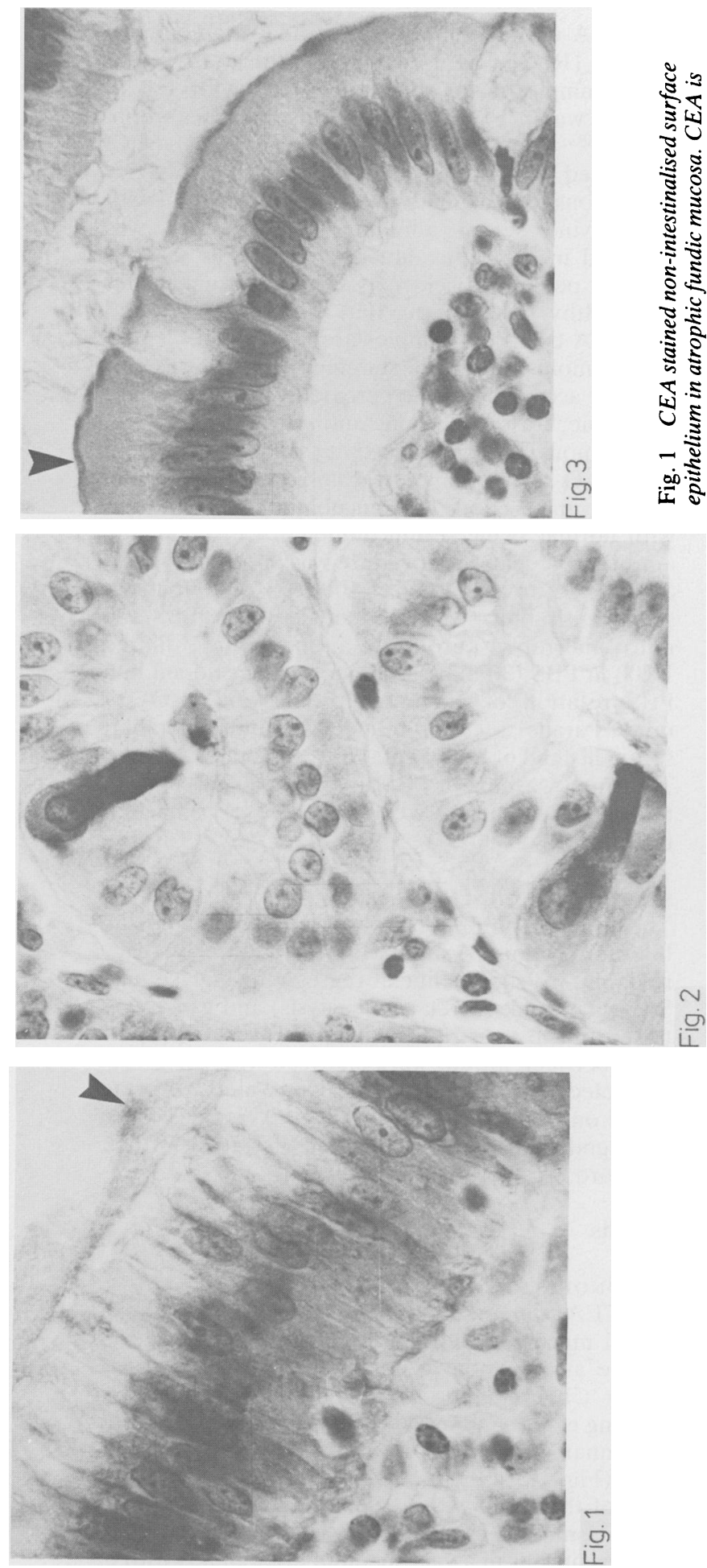
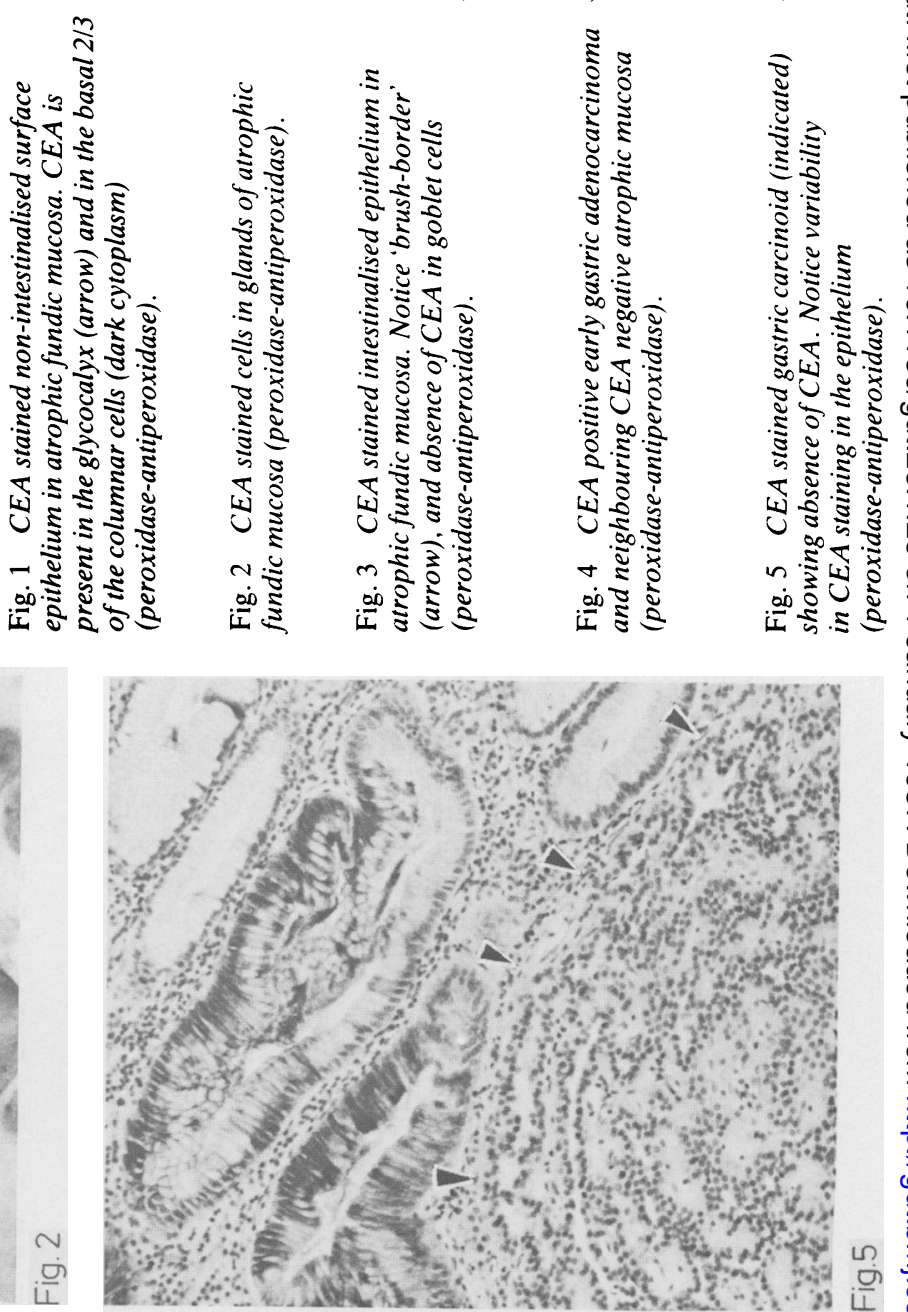

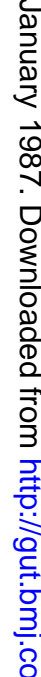

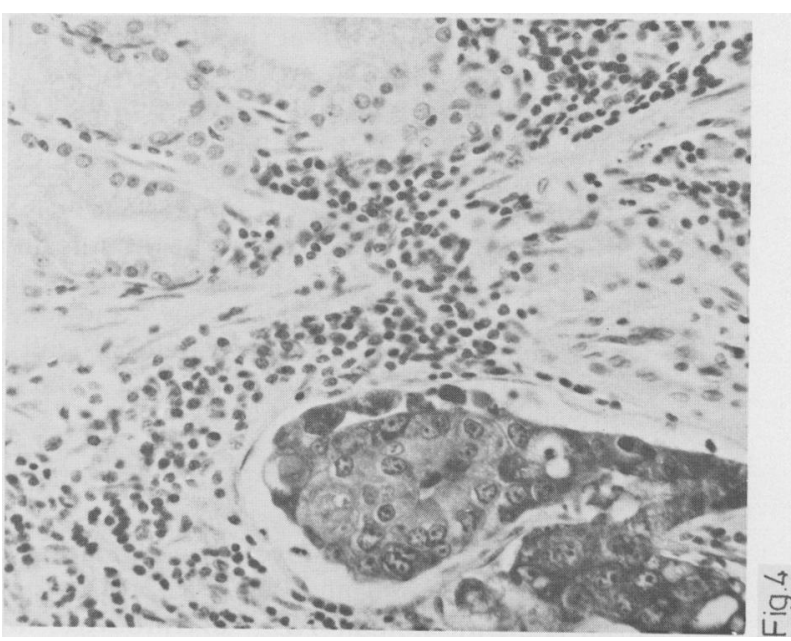

$\stackrel{9}{\mathrm{C}}$

$\overrightarrow{\overrightarrow{0}}$

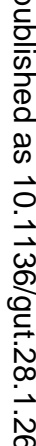

일 $\vec{c}$ 
without goblet cell metaplasia (intestinal metaplasia) (Fig. 2). Goblet cells showed no CEA staining (Fig. 3). When atrophy was present in the antral mucosa, the CEA staining resembled that in the atrophic fundic mucosa. The distribution and intensity of the CEA staining was not related to the degree of inflammatory reaction or milder degrees of epithelial dysplasia. The staining in regenerative polyps generally resembled that in the surrounding atrophic mucosa.

All adenocarcinomas showed CEA staining. In one case (intestinal type carcinoma), only few groups of malignant cells stained with a moderate intensity, but in the remaining cases a strong staining was observed in the cytoplasm of the majority of the tumour cells (Fig. 4). In the crater and margin of benign gastric ulcers, the CEA staining was slight or absent. In some areas of the gastric carcinoids, a slight homogenous cytoplasmic CEA staining was observed but the majority of the carcinoid tumour cells did not react to anti-CEA (Fig. 5).

\section{SERUM}

The serum CEA concentrations differed significantly between patients with atrophic gastritis without neoplasia $(16.5 \pm 0.9 \mathrm{ng} / \mathrm{ml})$ and normal controls $(12.9 \pm 1.0 \mathrm{ng} / \mathrm{ml})(\mathrm{p}=0.03)$ and between the former and patients with gastric neoplasia $(25 \cdot 7 \pm 4 \cdot 3 \mathrm{ng} / \mathrm{ml})$ $(p=0.03)$. Four patients without any known CEA producing disease, except atrophic gastritis,, had pathologically raised serum CEA $(25 \cdot 0-44 \cdot 0 \mathrm{ng} / \mathrm{ml})$. In five of the 10 patients with neoplasia, serum CEA concentrations were normal. Serum CEA concentrations were not related to gastric juice or tissue CEA levels in any group.

\section{GASTRIC JUICE}

No differences in gastric juice CEA concentrations related to intestinal metaplasia or inflammatory reaction in the gastric mucosa were noticed. Table 1 gives the mean gastric juice CEA concentrations in various subgroups. In atrophic gastritis the concentrations were increased above those in normal controls $(p<0.001)$. Considering patients with atrophic gastritis without neoplasia, those with achlorhydria seemed to have higher levels $(6450 \pm 1182 \mathrm{ng} / \mathrm{ml})$ than those with hypochlorhydria $(2508 \pm 617 \mathrm{ng} / \mathrm{ml})$, although $\mathrm{p}=0 \cdot 1$. In patients with atrophic gastritis and superimposed lesions (regenerative polyps, neoplasia or dysplasia), the concentrations were significantly higher than in patients without these lesions. In each subgroup of patients with superimposed lesions, the levels were higher than in patients with benign ulcer $(p<0.04)$.

Of all 61 patients with atrophic gastritis, $53(87 \%)$
Table 1 Concentration of carcinoembryonic antigen $(C E A)$ in gastric juice in normal control subjects $(C)$, in patients with benign gastric ulcer $(G U)$, and in subgroups of patients with fundic atrophic gastritis $(A G)$.

\begin{tabular}{|c|c|c|c|}
\hline Group & $\begin{array}{l}\text { Cases } \\
\text { (n) }\end{array}$ & $\begin{array}{l}\text { Mean } \pm \text { SEM } \\
\text { Gastric juice CEA } \\
\text { concentration } \mathrm{ng} / \mathrm{ml}\end{array}$ & $2 p$ \\
\hline $\mathrm{C}$ & 8 & $249 \pm 111$ & \\
\hline GU & 6 & $2019 \pm 1717$ & 0.08 \\
\hline $\begin{array}{l}\text { AG without super- } \\
\text { imposed lesions }\end{array}$ & 20 & $3538 \pm 1082$ & 0.002 \\
\hline $\begin{array}{l}\text { AG with neoplasia, } \\
\text { regenerative polyps, } \\
\text { or dysplasia }\end{array}$ & 41 & $7284 \pm 1184$ & \\
\hline $\begin{array}{l}\text { AG with regenerative } \\
\text { polyps }\end{array}$ & 23 & $7618 \pm 1899$ & \\
\hline AG with neoplasia & 10 & $7200 \pm 1869$ & NS \\
\hline AG with dysplasia & 19 & $8011 \pm 2075$ & NS \\
\hline
\end{tabular}

had gastric juice CEA values above the upper range $($ mean $+2 \mathrm{SD}=878 \mathrm{ng} / \mathrm{ml})$ of those in the normal controls. Of the 41 patients with superimposed lesions, $40(98 \%)$ had raised gastric juice CEA values, whereas $13(65 \%)$ of 20 patients without such lesions had raised values $(p=0 \cdot 001)$. One of six patients with benign gastric ulcer had a raised level.

TISSUE

Tissue CEA concentrations in various gastric lesions are given in Table 2. The lowest values were observed in carcinoid tumours and in benign ulcers. No significant difference was found between regenerative polyps and adenocarcinomas, or between regenerative polyps with epithelial dysplasia $(390.4 \pm 134.1 \mathrm{ng} / \mathrm{mg})$ and regenerative polyps without epithelial dysplasia (164.1 $\pm 30.5 \mathrm{ng} / \mathrm{mg})$.

In all patients and controls taken together, gastric juice CEA values were, to some extent, positively related to the values of tissue CEA in the fundic mucosa $(r=0.61, p<0.001)$, but not to those in the antral mucosa. No differences in tissue CEA concentrations related to the degree of atrophy, inflammatory infiltrate, or intestinal metaplasia were observed.

Neither fundic nor antral mucosal tissue CEA concentrations differed between any of the subgroups of patients with atrophic gastritis which, taken together, had significantly increased fundic $(113.2 \pm 12.7 \mathrm{ng} / \mathrm{mg})$, as well as antral $(242 \cdot 6 \pm 38 \cdot 0$ $\mathrm{ng} / \mathrm{mg}$ ) mucosal CEA concentrations, when compared with normal controls $(p<0.001$ and $p=0.03$, respectively). Of all 61 patients with atrophic gastritis, $44(72 \%)$ had fundic tissue CEA values 
Table 2 Concentration of carcinoembryonic antigen $(C E A)$ in the gastric mucosa in normal controls and in patients with fundic atrophic gastritis $(A G)$ without superimposed lesions, in various gastric lesions associated with $A G$, and in benign gastric ulcers.

\begin{tabular}{|c|c|c|c|}
\hline Lesion (area) & $\begin{array}{l}\text { Lesions } \\
\text { (areas) } \\
\text { (n) }\end{array}$ & $\begin{array}{c}\text { Mean } \pm S E M \\
\text { Tissue CEA } \\
\text { concentrations } \\
n g / m g\end{array}$ & $2 p$ \\
\hline Normal antral mucosa & 8 & $84 \cdot 7 \pm 17 \cdot 5$ & 0.07 \\
\hline Antral mucosa in $\mathrm{AG}$ & 20 & $212 \cdot 0 \pm 49 \cdot 1$ & \\
\hline $\begin{array}{l}\text { Antral regenerative polyps } \\
\text { Normal fundic mucosa }\end{array}$ & $\begin{array}{l}6 \\
8\end{array}$ & $\begin{array}{c}535 \cdot 0 \pm 199 \cdot 6 \\
21 \cdot 1 \pm 4 \cdot 8\end{array}$ & \\
\hline Fundic mucosa in $A G$ & 20 & $94 \cdot 1 \pm 18 \cdot 0$ & $\begin{array}{l}<0.001 \\
0.08\end{array}$ \\
\hline Fundic regenerative polyps & 19 & $164 \cdot 1 \pm 30 \cdot 5$ & $<0 \cdot 1$ \\
\hline Carcinoid tumours & 4 & $49 \cdot 0 \pm 5 \cdot 7$ & 0.01 \\
\hline Adenocarcinomas & 6 & $\begin{array}{l}268 \cdot 8 \pm 78 \cdot 6 \\
84 \cdot 3+18 \cdot 6\end{array}$ & $0 \cdot 02$ \\
\hline
\end{tabular}

above the upper range (mean $\pm 2 \mathrm{SD}=48.5 \mathrm{ng} / \mathrm{mg}$ ) of those in the normal controls, and $30(50 \%)$ antral tissue CEA values above the upper range $($ mean $+2 \mathrm{SD}=183.5 \mathrm{ng} / \mathrm{mg})$ of those in the normal controls.

\section{FOLLOW UP GASTROSCOPY}

Twenty six atrophic gastritis patients without neoplasia were re-examined. At the initial examination, gastric juice CEA values were raised in 23 , fundic mucosal tissue CEA values in 22 , and antral mucosal tissue CEA values in 17 of these 26 patients. During a mean follow up interval of 32 months (range 18-60 months), one patient had developed gastric adenocarcinoma, one adenoma, and two regenerative polyps. Of these four patients, all had raised gastric juice CEA values and two (adenocarcinoma and adenoma) raised mucosal tissue CEA values at the initial examination.

\section{Discussion}

In the present study, intestinal metaplasia was not divided into subtypes of which the colonic type is considered to be associated with increased CEA content. ${ }^{20}$ We did not detect CEA in goblet cells, however, and in agreement with the findings of others, ${ }^{17}$ we saw no general increase in the CEA staining in areas with goblet cell metaplasia. The tissue CEA concentrations were not related to the occurrence of intestinal metaplasia in parallel biopsy specimens.
With regard to the local CEA concentrations, the results of this study agree with those of others, ${ }^{721}$ and it was also shown that gastric juice CEA levels do not differ between patients with gastric adenocarcinoma and patients with pronounced atrophic gastritis. ${ }^{718} 21$ Mucosal CEA analysis showed a low sensitivity for atrophic gastritis or atrophic gastritis with superimposed lesions. Tissue CEA concentrations in the fundic mucosa were, to some extent, positively related to the gastric juice CEA concentrations, indicating that the gastric mucosal production of CEA is reflected in the gastric juice CEA content.

The content of CEA in gastric carcinoids was significantly lower than that in gastric adenocarcinomas and regenerative polyps. As routine histological examination generally allows differentiation between such lesions, the clinical relevance of any difference in the tissue CEA content between superimposed lesions would have been the occurrence of a corresponding difference in gastric juice CEA content. In the gastric juice of patients with atrophic gastritis, however, these differences in lesional CEA content seem to be overshadowed by the increased diffuse mucosal CEA production.

In atrophic gastritis, patients with superimposed gastric lesions had the highest gastric juice CEA concentrations. With regard to patients with dysplasia or adenocarcinoma, these findings agree with those of others. ${ }^{21}$ It seems that an increased proliferative and metaplasiogenic activity, indicating a premalignant change in atrophic gastritis, is associated with increased local production of CEA. Conversely, assuming that increased production of CEA is an expression of premalignant change, it appears that patients with atrophic gastritis and superimposed lesions are at special risk of developing neoplasia.

Although the group of normal control subjects was small for a definite determination of normal range, one may assume that screening with the easily done analysis of gastric juice CEA would identify the majority $(87 \%)$ of individuals with fundic atrophic gastritis and practically all $(98 \%)$ individuals with atrophic gastritis and associated neoplasia, dysplasia, or regenerative polyps. Of 26 rescreened patients, 23 initially had raised gastric juice CEA values and, of the latter, two had developed regenerative polyps, one adenoma, and one adenocarcinoma. Further follow up studies are needed to determine whether, as indicated here, patients with atrophic gastritis and raised gastric juice CEA, have a higher risk of developing neoplasia than those with atrophic gastritis and normal gastric juice CEA. If this is so, screening of gastric juice CEA during routine gastroscopy could 
aid in the identification of patients in need of regular gastroscopic screening.

The study was supported by grants from The Swedish National Cancer Association (1766-B83-01XA).

\section{References}

1 Gold P, Freedman SO. Demonstration of tumorspecific antigens in human colonic carcinomata by immunological tolerance and absorption techniques. $J$ Exp Med 1965; 121: 439-62.

2 Gold P, Freedman SO. Specific carcinoembryonic antigens of the human digestive system. $J$ Exp Med 1965; 122: 467-81.

3 Goldenberg DM, Neville AM, Carter AC, et al. $C E A$ : its role as a marker in the management of cancer. Consensus Development Conference Statement. Bethesda, Maryland, USA: National Institutes of Health, 1980.

4 Hansen HJ, Snyder JJ, Miller E, et al. Carcinoembryonic antigen (CEA) assay. A laboratory adjunct in the diagnosis and management of cancer. Hum Pathol 1974; 5: 139-47.

5 Hirai H, Nishi S. Carcinoembryonic antigen: Its determination and clinical data. In: Farber E, et al, eds. Pathophysiology of carcinogenesis in digestive organs. Tokyo: Univ Tokyo Press 1977: 247-58.

6 Gold P. Circulating antibodies against carcinoembryonic antigens of the human digestive system. Cancer 1967; 20: 1663-7.

7 Bunn PA, Cohen MI, Widerlite L, Nugent JL, Matthews MJ, Minna JD. Simultaneous gastric and plasma immunoreactive carcinoembryonic antigen in 108 patients undergoing gastroscopy. Gastroenterology 1979; 76: 734-41.

8 Goldenberg DM, Sharkey RM, Primus FJ. Carcinoembryonic antigen in histopathology: immunoperoxidase staining of conventional tissue sections. $J$ Natl Cancer Inst 1976; 57: 11-22.

9 Khoo SK, Warner NL, Lie JT, Mackay IR. Carcinoembryonic antigen activity of tissue extracts: a quantitative study of malignant and benign neoplasms, cirrhotic liver, normal adult and fetal organs. Int $J$ Cancer 1973; 11: 681-7.

10 Martin F, Martin MS. Radioimmunoassay of carcinoembryonic antigen in extracts of human colon and stomach. Int J Cancer 1972; 9: 641-7.

11 Satake K, Yamashita K, Kitamura T, Tei Y, Umeyama $\mathrm{K}$. Carcinoembryonic antigen-like activity in gastric juice and plasma in patients with gastric disorders. $\mathrm{Am}$ J Surg 1980; 139: 714-8.

12 Tatsuta M, Itoh T, Okuda S, Yamamura H, Baba M, Tamura $\mathrm{H}$, Carcinoembryonic antigen in gastric juice as an aid in diagnosis of early gastric cancer. Cancer 1980; 46: 2686-92.

13 Burtin P, von Kleist S, Sabine MC, King M. Immunohistological localization of carcinoembryonic antigen in gastrointestinal normal and tumoral tissues. Cancer Res 1973; 33: 3299-305.

14 Burtin P, Sabine MC, Chavanel G. A comparative study of the localization of CEA and $\mathrm{NCA}_{2}$ in cancerous and normal gastointestinal tissues. Int $J$ Cancer 1977; 19: 634-41.

15 Denk H, Tappeiner G, Davidovits A, Holzner JH. The carcinoembryonic antigen (CEA) in carcinomata of the stomach. Virchows Arch [Pathol Anat] Abt A 1973; 360: $339-47$.

16 Ejeckam GC, Huang SN, McCaughey WTE, Gold P. Immunohistopathologic study on carcinoembryonic antigen (CEA) - like material and immunoglobulin A in gastric malignancies. Cancer 1979; 44: 1606-14.

17 Janunger KG, Lindgren J, Sipponen P, Domellöf L. Carcinoembryonic antigen (CEA) in the gastric mucosa after partial gastrectomy. Scand J Gastroenterol 1979; 14: $555-60$.

18 Kojima O, Tanioku T, Kitagawa N, et al. Immunoreactive carcinoembryonic antigen in gastric juice in patients with gastric cancer. Jpn J Surg 1983; 13: 324-30.

19 Nielsen K, Teglbjaerg PS. Carcinoembryonic antigen (CEA) in gastric adenocarcinomas. Acta Pathol Microbiol Immunol Scand 1982; 90 [sect A]: 393-6.

20 Nielsen K, Teglbjaerg PS. On the occurrence of carcinoembryonic antigen (CEA) in different types of intestinal metaplasia of the human stomach. Tumour Biol 1984; 5: 313-20.

21 Nitti D, Farini R, Grassi F, et al. Carcinoembryonic antigen in gastric juice collected during endoscopy. Cancer 1983; 52: 2334-7.

22 Sipponen P, Ruoslahti E, Vuento M, et al. CEA and CEA-like activity in gastric cancer. Acta HepatoGastroenterol 1976; 23: 276-9.

23 Kawai K, Sasaki Z, Misaki F, Ida K, Kubota Y. Endoscopic diagnosis of intestinal metaplasia of the stomach and its evaluation as a precancerous lesion. Front Gastrointest Res 1979; 5: 140-8.

24 Borch K, Renvall H, Liedberg G. Gastric endocrine cell hyperplasia and carcinoid tumours in pernicious anemia. Gastroenterology 1985; 88: 638-48.

25 Borch K. Epidemiologic, clinicopathologic, and economic aspects of gastroscopic screening in patients with pernicious anaemia. Scand J Gastroenterol 1986; 21: 21-30.

26 Kaplan HS, Rigler LG. Pernicious anemia and carcinoma of the stomach-autopsy studies concerning their interrelationship. Am J Med Sci 1945; 209: 339-48.

27 Mosbech J, Videbaek Aa. Mortality from and risk of gastric carcinoma among patients with pernicious anaemia. $\mathrm{Br}$ Med J 1950; 2: 390-4.

28 Siurala M, Erämaa E, Tapiovara J. Pernicious anemia and gastric carcinoma. Acta Med Scand 1959; 164: 431-6.

29 State D, Gaviser D, Hubbard TB, Wangensteen $\mathrm{OH}$. Early diagnosis of gastric cancer. JAMA 1950; 142: 1128-33.

30 Stockbrügger RW, Menon GG, Beilby JOW Mason RR, Cotton PB. Gastroscopic screening in 80 patients with pernicious anemia. Gut 1983; 24: 1141-7.

31 Zamcheck N, Grable E, Ley A, Norman L. Occurrence of gastric cancer among patients with pernicious anemia at the Boston City Hospital. $N$ Engl J Med 1955; 252: 1103-10. 
32 Borch K, Liedberg G. Prevalence and incidence of pernicious anemia. An evaluation for gastric screening. Scand J Gastroenterol 1984; 19: 154-60.

33 Jacobsen M, Clausen PP, Smidth S. The effect of fixation and trypsinization on the immunohistochemical demonstration of intracellular immunoglobulin in paraffin embedded material. Acta Pathol Microbiol Scand 1980; 88: 369-76.

34 Öst $\AA$, Ewerth S, Hellers G. Intestinal metaplasia in the gastric remnant following resection for benign ulcer disease: a comparison between morphology and histochemistry. Acta Chir Scand 1980; suppl 500: 23-7.

35 Morson BC, Sobin LH, Grundman E, Johansen E, Nagayo T, Serck-Hansen A. Precancerous conditions and epithelial dysplasia in the stomach. J Clin Pathol 1980; 33: 711-21.

36 Whitehead R, Truelove SC, Gear MWL. The histolo- gical diagnosis of chronic gastritis in fibreoptic gastroscope biopsy specimens. J Clin Pathol 1972; 25: 1-11.

37 Laurèn $P$. The two histological main types of gastric carcinoma: Diffuse and so-called intestinal type carcinoma. Acta Pathol Microbiol Scand 1965; 64: 31-49.

38 Murakami T. Early gastric cancer. Gann Monograph on Cancer Research 11. Tokyo: Univ Tokyo Press, 1971.

39 Zimmerman R, Wahren B, Edsmyr F. Assessment of serial CEA determinations in urine of patients with bladder carcinoma. Cancer 1980; 46: 1802-9.

40 Zimmerman R. Improved performance of a double antibody radioimmunoassay for carcinoembryonic antigen. J Immunol Meth 1979; 25: 311-21.

41 Sternberger LA. The unlabeled antibody enzyme method. In: Sternberger LA, ed. Immunocytochemistry. Englewood Cliffs, NJ: Prentice Hall, 1974; 129-71. 